Ärztliche Erfahrung beschränkt sich nicht auf medizinisches Fachwissen.

Sie entsteht auch aus den mehr oder minder alltäglichen, heiter, ärgerlich oder nachdenklich stimmenden Erlebnissen mit Patienten, Kollegen und Mitarbeitern. Senden Sie uns Ihre Geschichte an: cornelius.heyer@springer.com.

\title{
Gut, dass es den MDK-Bericht gibt!
}

Eine meiner Patientinnen brauchte eine Psychotherapie. Sie war motiviert, und nach wenigen probatorischen Sitzungen konnten wir uns ein genaues Ziel erarbeiten. Zeitgleich wurde ein Platz in der Therapiegruppe frei, und so stellte ich einen Psychotherapieantrag an die Krankenkasse.

Meist werden diese Anträge innerhalb von zwei Wochen bewilligt - dieser hier aber nicht. Eine telefonische Nachfrage erbrachte nur die Auskunft, dass der Antrag noch in Bearbeitung sei.
Nach vier Wochen hatte sich immer noch nichts getan.

Als ich kurz davor war, den Platz jemand anderem zu geben, tat sich dann doch etwas - aber nicht das, was ich erhofft hatte. Der MDK verlangte von mir einen Verlaufsbericht der Psychotherapie. Gewöhnlich gehört das nicht zu meinen favorisierten Arbeiten, aber in diesen speziellen Bericht konnte ich ja nicht viel schreiben, weshalb ich ihn unmittelbar verfasste. Ich hielt die Diagnose fest und erklärte, dass ich noch nichts zum Verlauf der Therapie sagen könne, da sie in den vier Wochen seit der Antragstellung noch nicht bewilligt worden war. Noch am selben Tag verschickte ich den Bericht mit der Post - und genau vier Tage später landete die Bewilligung endlich in unserem Briefkasten.

Ich denke, dass wohl der MDK diese Beschleunigung bewirkt hat. Vielleicht zum ersten Mal war ich froh darüber, dass es die MDK-Berichte gibt.

Dr. Luise Hess, Darmstadt

\section{Welche Pille hilft bei „hängendem Blümchen“?}

_ Obwohl ich eine Frau bin, sprechen meine männlichen Patienten mir gegenüber immer recht offen über ihre Probleme im sexuellen Bereich. Als Ärztin habe ich natürlich auch immer ein offenes Ohr. Einer meiner Patienten z. B. leidet aufgrund einer Wirbelsäulen-OP an Erektionsproblemen. Er greift deswegen regelmäßig dankbar auf seine bewährten „blauen Tabletten“ zurück.

Neulich kam er zu mir in die Praxis, da er mal wieder eine Verschreibung brauchte. Er bat also meine neue Arzthelferin um ein "Sildenafil-Rezept“. Ihr sagte der Name des Wirkstoffs aber nichts, weil sie frisch aus der Kinderklinik zu mir gekommen war. Im Computer sah sie nur, dass es sich dabei um ein Privatrezept handelte, und auch die $\mathrm{Pa}$ - ckungsgröße gab ihr keinen Hinweis darauf, um welches Medikament es sich wohl handeln könnte. Deshalb fragte sie ganz unbedarft, wie oft er denn die Tabletten nehme und warum. Er hatte diese Frage nicht erwartet und wusste erst nicht recht, was er sagen sollte. Doch dann fing er an zu grinsen, lehnte sich mit beiden Armen auf den Tresen und sagte: „Wissen sie, es gibt doch die Bienchen und die Blümchen." Dann senkte er die Stimme und raunte ihr zu: „Und manchmal kommt es eben vor, dass die Blümchen den Kopf hängen lassen.“

Ingrid Maschke, Pforzheim
Mit Bienchen und Blümchen sollten Ärzte sich auch auskennen. 